\title{
"Hunting on the Streets": Masculine Repertoires Among Israeli Clients of Street-Based Sex Work
}

\author{
Yeela Lahav-Raz ${ }^{1}$ iD \\ Published online: 7 August 2019 \\ (c) The Author(s) 2019
}

\begin{abstract}
In this article, I discuss the unique masculine repertoire of Israeli clients of streetbased sex work. In doing so, I aim to reveal the deep meaning of sex consumption on the street while reflecting on the way in which universal and local masculine repertoires are negotiated and contested. Based on a discourse analysis of online sexual reports, the article focuses on clients' metaphoric language of themselves as hunters when describing sexual encounters on the street, arguing that the hunting metaphor has become a channel through which a community of "warriors" has been built. The sexual script of the hunter is a mixture of intersecting characteristics from the universal dominant repertoire of hegemonic, heteronormative hyper-masculinity with characteristics from the two Israeli masculine hegemonic repertoires: the combat soldier and the Halutz (pioneer). The sexual script of the hunter thus functions as a platform on which other relations of power, especially between men themselves, are played out and contested.
\end{abstract}

Keywords Masculinity $\cdot$ Hegemonic masculinity $\cdot$ Street-based sex work $\cdot$ Clients · Online communities · Israeli society

\section{Introduction}

The question of what men are purchasing when they pay for sexual encounters has been the subject of extensive debate (Joseph and Black 2012). As argued by many (Bernstein 2001, 2007; Cabezas 2009; Earle and Sharpe 2008a; Hoang 2011; Huysamen and Boonzaier 2015; Jones and Hannem 2018; Katsulis 2010; Milrod and Weitzer 2012; Sanders 2008, 2012; Zheng 2009), sex work is not just an economic transaction but also involves emotional intimacy which, according to Sanders (2012), is not necessarily different in content from that of non-commercial sexual relationships in which emotional and physical intimacies are produced and

Yeela Lahav-Raz

ylr4@leicester.ac.uk

1 Criminology Department, University of Leicester, 36 Hartopp Road, Leicester LE21WE, UK 
consumed. While the perception of the commercial sexual encounter as part of the "transformation of intimacy" (Sanders 2012) is well documented and argued, it is usually associated with indoor settings and venue-based sectors of the sex industry. Since indoor sex work tends to be of longer duration with more repeat and regular customers (Joseph and Black 2012), it has been claimed that recreational and intimate exchanges can develop (Hoang 2011).

Conversely, outdoor settings such as street-based sex work are, due to their spatial characteristics, usually viewed as "pure" economic exchanges, focusing on the exchange of physical, sexual acts for money. By drawing on discourse analysis of an online community of Israeli sex industry clients, and focusing on their use of metaphoric language to describe sexual encounters on the street, this article aims to advance a more complex and diversified understanding of both the meaning of consumption sex on the street and the way in which Israeli male clients use the online arena to negotiate their identities in accordance with local and universal repertoires of masculinity.

The theoretical inspiration for this article is a combination between Swidler's (1986) definition of culture repertoire as a "toolkit" of habits, skills, and styles from which people construct strategies of action and Simon and Gagnon's (1986, 2005) sexual script theory, according to which sexual behaviours derive from metaphorical scripts learned and incorporated by individuals as a function of their involvement in the social group (Wiederman 2015). Empirical data from an Israeli online forum shows hunting to be the main metaphor used by Israeli clients to describe their sexual encounters on the street. In contrast to their online discussions about indoor sex work venues, when clients write about their sexual encounters on the street, they refer to themselves as "hunters" (Hebrew: tzayadim) and provide detailed descriptions of kerb-crawling as a pre-planned ritual involving emotions such as excitement, thrill, anticipation, and overcoming fear. In this article, I question why Israeli clients of street-based sex work are using the sexual script of the hunter as their main cultural repertoire and what it can teach us about the meaning of purchasing sex on the street and the way in which masculine repertoires are negotiated and contested.

Israeli clients of street-based sex work demonstrate, I claim, flexible masculinity that draws from both local and universal repertoires alongside the specific situated social contexts of the street. The sexual script of the hunter is a mixture of intersecting characteristics from the universal dominant repertoire that constructs men as having a biological, urgent and insatiable need for sex that must be regularly satisfied (Sanders 2008), combined with characteristics from the two Israeli masculine hegemonic repertoires: the combat soldier (Sasson-Levy 2002, 2008) and the Halutz (pioneer) (Hirsch 2014), both of which are bound up with racialized social hierarchies. Furthermore, the metaphoric language used in online arenas conceptualises the sexual script of the hunter as a mental representation individuals construct and then use to make sense of their experiences on the streets including their own and others' behaviours. Thus, the common representation online transforms the private sexual act into a collective sexual ritual in which men's paid sexual encounters on the street function as a platform on which other relations of power, especially between men themselves, are played out and contested. 


\section{Review of the Literature}

\section{Street-Based Sex Work}

Although there is extensive literature on the characteristics and motivations of clients of commercial sex (Earle and Sharpe 2008a; Huysamen and Boonzaier 2015; Joseph and Black 2012; Katsulis 2010; Milrod and Weitzer 2012; Sanders 2008), most of those studies have focused on consumers who buy sex from women working at off-street locations. According to Shumka et al. (2017), the absence of literature on men who purchase street-based sex, represents a bias on the part of researchers who see them as a less relevant population to study. The perception of buying sex on the street as a casual and opportunistic activity shifts the focus from the clients and onto sex workers.

Studies have shown that street-based sex work is typically more dangerous than indoors sex work and involves stigmatised and marginalised populations with little state protection (Brents and Sanders 2010; Ellison and Weitzer 2017; Oselin and Cobbina 2017; Weitzer 2012). According to Sanders (2004), streetbased sex work has three main occupational hazards: violence from male clients, issues relating to policing, and community protesters. Much attention has been given to the impact of gentrification on sex workers (Hail-Jares et al. 2017), coping strategies for minimizing the risks of violence, arrest, and exploitation (Armstrong 2014; Hubbard and Sanders 2003; Oselin and Cobbina 2017; Sanders 2001), the psycho-social implications attached to the hazards of street-based sex work (Gorry et al. 2010), and the impact of sex work policy on street-based sex workers (Sagar 2009; Sagar and Croxall 2012; Sagar and Jones 2013).

While researchers have examined various aspects of street-based sex workers, there is a paucity of research exploring clients' perceptions of their activity on the street. Most of the studies on street clientele were based on data gathered from arrested male clients forced to participate in rehabilitation programs. Researchers highlighted demographic features of this population, as well as the socioeconomic determinants and psychosocial motivations for purchasing sex (BrooksGordon and Gelsthorpe 2003; Busch et al. 2002; Della Giusta et al. 2009; Monto and McRee 2005). Since the sexual encounter on the street is considered a marginal and declining sector that contains quick and impersonal "sexual release" (Bernstein 2001), scholars have been less attuned to the (potentially) deep meaning of purchasing sex on the street. The exceptions to these are the studies of Vaughn (2019) on systems of power and their influence on South African clients and Shumka et al. (2017) on hegemonic masculinity concerning the purchase of street-level sex. Both studies emphasise different aspects of hegemonic masculinity. Vaughn (2019) show how clients tended to discuss outdoor sex workers as objects one purchases rather than an individual providing services, hence suggesting that clients' perception of their own (structural or interpersonal) power within the sex work transaction may empower clients to enact violence to achieve their desired end. Shumka et al. (2017) argue that the purchase of street-level sex is motivated by a sense of failure to successfully align with classed and gendered 
norms of hegemonic masculinity in which the purchase of sex was an attempt to "feel like a man again". Thus, the purchase of street-level sex can both confirm and undermine the sense of manhood.

As highlighted in previous findings, for example, "the sex industry is not simply about selling sex and sexual fantasies; rather it is also about attending to the emotional needs of male clients" (Sanders 2008, p. 413), I aim to show that for Israeli clients, the consumption of street-based sex services goes beyond the mere exchange of money for sex. Although relationships between sex workers and clients in streetbased sex work are short-term, for some, it is still a pre-planned and calculated behaviour. It contains various rituals and practices which are consistent with the clients' emotional needs such as the establishment of a male brotherhood; the need for imposing male power and competitiveness in front of others. It is less about their relationship with sex workers and more about their ability to actively use the online arena to negotiate their masculine identities and practices in front of others. This is closely related to the fact that masculinity receives its validation not from women but rather from other men (Bourdieu [1998] 2001, p. 52; Kimmel 1996, p. 7).

Furthermore, paying for sex on the street and writing about it online not only reproduces and reinforces (universal) patriarchal heteronormative discourses (Huysamen 2018; Huysamen and Boonzaier 2015; Sanders 2008) but also attends to the emotional need to feel part of the ideal of hegemonic repertoires of Israeli masculinity — an ideal which the individuals may not experience in their daily lives.

\section{Sexual Scripts and Masculine Repertoires}

Gagnon and Simon's (2005) seminal work on sexual scripts identified how various cultural narratives and socialisations impact the context, shape, and experience of sexual encounters. For Gagnon and Simon (2005), interpersonal scripting draws on shared symbols and cultural expectations about sex and sexuality to permit individuals to interact and play out a "scene" without necessarily explicitly discussing the parameters of that interaction. Drawing on the sexual script theory, Jones and Hannem (2018) argue that male clients of sex workers at once are pursuing the appropriate cultural script of seeking sexual interaction with (often multiple) desirable women, but violating scripts of romantic sexuality which suggest that such encounters should be organic, rooted in mutual desire, and free of (explicit) commodification. However, they suggest that at the subsequent layers of scripting-interpersonal and intrapsychic scripting - sex workers and clients construct interactions that draw on these dominant cultural scripts, rewriting the script in a way that sets the boundaries of the encounter and allows for clients to experience intimacy within a bounded temporal and emotional frame. While researchers were more attuned to the intimacy within the sex worker-client interaction, I aim to reveal the way Israeli clients are using the sexual script of the hunter to create intimacy among other members of the online community.

Since the sexual script theory go as far as to guide how the individual should feel and behave (Burghart 2018), much attention has been given to gender differences regarding cultural, social and sexual scripts. Masculine gender roles have 
long dictated power, general independence, assertiveness and exploration as the typically hegemonic masculine ideals. In this article, I adopt Swidler's (1986) notion of masculinity as a cultural repertoire, from which people make situated selections. According to Hirsch and Grosswirth Kachtan (2017), the repertoire of masculinity is where the elements and models that organise both masculine practice and perceptions concerning masculinity are stored. The notion of "repertoire" shifts the focus from the more rigid notion of "masculinities" to the flexible terrain of situated social practice, which makes use of available models in specific contexts. Thus, it allows considering masculinity both as a normalising cultural ideal and as a relational and contextual social practice, without reducing it to either. It is highly relevant when analysing Israeli masculine repertoires.

The construction of Israeli masculinity combines two repertoires. The first, the Halutz, stems from a Zionist ideology which prioritises masculine values like self-sufficiency, courage, endurance, abstemiousness, and the pursuit of honour (Hirsch 2014; Hirsch and Grosswirth Kachtan 2017). The second is the combat soldier, creating men out of boys and hence linked to training masculinity (Kronsell 2015). Since serving in the army is mandatory in Israel, the combat soldier has become a symbol for preeminent masculinity, functioning as a major channel for male social mobility (Kaplan 2003; Lomsky-Feder and Rapoport 2003; Sasson-Levy 2003, 2008). The two repertoires are bound together since service in the Israeli military is seen as the primary rite of passage that initiates adolescent boys into full membership of the masculine civil religion of Zionism (Mazali 1993; Ben-Ari and Levy-Schreiber 2000).

The combination of these two repertoires creates cultural components-such as national pride, the conquest of land through labour, a combative spirit, physical power, and masculinity - that are impossible to disentangle. Thus, both the Halutz and the combat soldier belong to the pantheon of masculine symbols in Israel (Hirsch and Grosswirth Kachtan 2017). Both repertoires are consistent with Israel's national hierarchical structure which, according to Hirsch and Grosswirth Kachtan (2017), is racialised with Ashkenazi Jews at the top, Mizrahi Jews in the middle, and Palestinian Arabs at the bottom. In hegemonic Israeli culture, this racialised hierarchy is taken to correspond to the hierarchy of civilisation.

The dominance of these two repertoires raises the question of why Israeli clients of street-based sex work use the sexual script of the hunter as their main cultural repertoire and not the Halutz or the combat soldier. The concept of the hunter is interesting precisely due to its absence from Israeli hegemonic masculine ideals. I argue that the sexual script of the hunter allows clients to connect to hegemonic Israeli masculinity while ignoring and blurring its inherent racialised social hierarchies. While in other areas of life the questions of whether an individual belongs to the "right" ethnic group or whether he served as a combat soldier are ever-present, these questions are not relevant in online discussions about the consumption of sex. The need to feel part of the hegemonic group and to create camaraderie with other men does, however, exist. Thus, even if clients are not members of the hegemonic social strata in their everyday lives, under the anonymity intrinsic to the online community, the sexual script of the hunterwhich combines both universal and local repertoires-allows them to perform 
and guarantee a masculine self in front of others while claiming any identity imaginable.

\section{Research Field and Methods}

The findings of this article are part of a larger research project conducted between 2012 and 2015 about masculine repertoires among Israeli sex industry clients (Lahav-Raz 2016, 2017, 2019a). As part of the research, a discourse analysis of online reports of Israeli sex clients' community has been made. Such analysis did not argue for or against the 'truth' of specific statements in the text; rather, it focused on the existence and message of the texts and then located them within a historical and social context (Caldas-Coulthard 1993). As part of the research, I examined the role of language ${ }^{1}$ in creating a particular reality as well as the social relationships and ideologies that are promoted through speech.

This community was part of an Israeli internet sex portal which offered diverse sex services, among them an extensive array of 28 client review forums in which individuals can discuss a variety of problems or issues. Among the 28 forums, 24 were open and could be read by everyone, but in order to write a review, registration with a username and password was necessary. The data for the current article was taken from an open and public forum called "Street Forum," then the third largest forum on the site. It contains the experiences and reviews of Israeli clients of streetbased sex consumption, especially in the city of Tel Aviv. All posts in this study were sampled within a year, between 2012 and 2013, with a total of 160 posts collected and analysed.

The growing body of research about online communities of sex industry clients (Blevins and Holt 2009; Holt and Blevins 2007; Horswill and Weitzer 2018; Huff 2011; Tyler and Jovanovski 2018) has defined ethical issues relating to consent, permission, and privacy. According to these studies, when a site defines itself as open and public, no user consent is required for the research. However, as Sanders et al. (2009) claimed, studying the online performances of sex industry clients brings ethical, methodological, and epistemological complications into this form of research. Therefore, even though consent was implied, all nicknames (although anonymous) and any other identifying details of the website or the writers have been erased from the quotations in order to maintain confidentiality.

Although there is no official red-light district in Israel and the country is going through changes regarding sex-work policy (from decriminalisation to a softened version of the Nordic law ${ }^{2}$ ), street-based sex arenas are generally left undisturbed by

\footnotetext{
${ }^{1}$ For a more detailed discussion on how language creates reality, see: Agar (1994), Ostriker (1986), and Spender (1980).

2 On December 31, 2018, the Israeli parliament passed the 'Prohibition on Consumption of Prostitution Law'. According to the new law (which will be enacted in 2020), there will be only administrative fines with a voluntary alternative of participating in a preventive training course and no criminal record. For a more detail discussion about current changes regarding sex work policy in Israel, see: Lahav-Raz (2019b).
} 
the police, except for occasional random raids. Most of the street-based sex work in Israel takes place in urban areas in the centre of the country, especially in the coastal city of Tel Aviv. As in many other red-light districts around the world, these are both multinational and multiethnic areas with low socioeconomic veteran residents and an influx of refugees and immigrants from various countries.

Information on the clientele of street-based sex work in Israel is absent. According to a national survey published in 2016 (Santo et al. 2016), which was the first in Israel's history and serves as the only available statistical information, the number of people working in prostitution was estimated at over 12,000, of whom $95 \%$ were women. Among the various prostitution scenes, street-based sex work was found to constitute a total of $7 \%$, with most sexual encounters taking place in indoor settings such as discreet apartments, strip clubs, escort and massage parlours. While the survey ignored the characteristics of sex industry clients, it did highlight the characteristics of street-based sex workers. The estimated number of adult women in street-based sex work was 690 women. The estimated cost of street-based sex work is about NIS 60 million, about $5 \%$ of all customer payments for sex services. According to the national survey, $58 \%$ of women working on the street are nativeborn Israelis, and 33\% were born in the former Soviet Union. The only data provided about street clientele is that the street-based sex work scene, despite being the smallest of all prostitution scenes in Israel, comprises the highest number of clients of all the sectors examined in the survey, with an average of 6.8 clients on a workday. ${ }^{3}$

\section{Findings}

\section{The (Deep) Meaning of "Hunting" on the Street}

Not all men seek sex workers for the same reasons, and different types of men have different values and attitudes toward the meaning of purchasing commercial sex. However, the spatial characteristics of the street, where clients can view others (albeit by car) while engaging in sexual encounters, offer a unique experience that cannot take place in indoor settings nor the clients' daily lives. In such an atmosphere, the online arena takes on many different functions. It serves as both a socialisation and legitimisation mechanism (Horswill and Weitzer 2018) and a platform on which the individual can express his deepest inner self. Due to the "online disinhibition effect" (Suler 2004) combined with the taboo of sex consumption on the street, the online community provides men with a temporary fantasy world of belonging to the privileged group that he may not experience in his daily life. Men may signal a masculine self via a variety of strategies. Since successful masculine gender identities are associated with sexual voraciousness and men's high sex drive is constructed within western culture as a "biological need" that demands satisfaction via quick sexual release (Sanders 2008), in the norms and practices of the Israeli subcultural

\footnotetext{
3 The average number of clients in discreet apartments and escort services is 5.2 per day and in massage parlors 6 per day.
} 
toolkit, the hunting metaphor has become the common way for clients to describe their activities on the street. Some of the clients use the hunting metaphor as a validating mechanism to justify their ancient and universal male instinct:

Listen, Lieutenant. I'll try to take the matter seriously. You're a hunter like all of us. We were all hunters in our past. (May 30, 2012)

The hunter's instinct has always been in the man since the dawn of evolution. (May 22, 2012)

Alongside enabling men to connect to this universal repertoire of ancient masculinity, the hunting metaphor also serves as a way of expressing aspects of their personality which they cannot express in their everyday lives, thus revealing the deep meaning of street-based sex consumption: "I think that for me, the hunt, apart from the adrenalin, comes to satisfy some other aspect of my personality that is not expressed on a daily basis. (March 14, 2013)". The unexpressed aspect of this client's personality is the yearning for the thrill, in other words, intense feelings, both emotional and physical, that derive from extraordinary experiences that are perceived as inaccessible in everyday life and can only be achieved through the consumption of sex on the street.

With all the mileage I have gained over the years on the streets, I am still thrilled by what the street has to offer, what a fascinating world exists under all of our noses - a world with a lot of stink, evil, and humiliation but also with lots of beauty and, especially, endless possibilities.(August 8, 2012)

The thrill achieved from street-based sex consumption is consistent with SassonLevy's (2008) findings of the importance of thrill in the Israeli military experience. While militarised masculinity demands emotional control, military life nonetheless provides unique opportunities for experiencing the extraordinarily deep feeling of thrill. Sasson-Levy's findings highlight four sources of the thrill achieved through the military experience: self-sacrifice, the sense of having control over weapons and technology, the feeling of youthful adventure, and homosociality. Clients of streetbased sex work embrace the sense of thrill as a way of experiencing the excitement of what they consider a dangerous situation. Although the law to incriminate clients will only be enacted in 2020, purchasing commercial sex is still considered as a social and cultural taboo in Israel society. Thus, clients are worried about being publicly shamed and exposed, especially if they have formal relationships. Furthermore, the sensations of tremendous excitement, thrill, anticipation, conquest, and overcoming fear can be so intense that they supersede the sex itself:

It all began at a fairly early age...probably around 17, the first time....It began in [brothels] and shifted to the street, not for financial reasons but hunting considerations....The huge excitement, the current flowing through the body and brain, the fear, overcoming the fear, and a host of emotions and various gratifications. The conquest, the occasional disappointment which may come from a failure in hunting or even from success...the satisfaction I found on the street, I couldn't find in other places. I have spent long nights on the city streets. Hunting. Hunting. Hunting. (March 13, 2013) 
This quote reveals that even in sex on the street, clients actively seek, both physically and emotionally, experiences with which to constitute and assert themselves. This testimony portrays street-based sex consumption as a mythical adventure on which the hunter-hero embarks from the everyday world into a wondrous supernatural world. It is a time-out experience, escaping his everyday and being, albeit briefly, in a different reality. In addition to enabling the expression of unmet emotional needs, the hunting metaphor has also become a communal "trademark" that serves the emotional needs of the individual, which go beyond the financial reasons for choosing sex on the street to encompass the need to feel part of a community:

The stuff you write here is something we all go through on the hunter's evenings, and that's something that makes it even cooler. (July 14, 2012)

During the hunt, I saw that I had received a message from some group members. It was fun to get reports and to communicate with a group like me looking for hunting. (February 11, 2012)

Friends...your hunting reports are amazing! That's exactly what I've been looking for years. (November 11, 2012)

As in the army, where emotional intimacy among men is allowed and even encouraged, street-based sex consumption and, in particular, the ability to write about it online serves as a platform through which men can achieve intimacy with each other by using the same sexual script. Studies have repeatedly highlighted the desire for emotionality and authenticity within the client-sex worker encounter (Bernstein 2007; Earle and Sharpe 2008b; Katsulis 2010; Milrod and Weitzer 2012; Sanders 2008), which is often referred to as "the girlfriend experience" that most closely mimics traditional heterosexual dating scripts. Data gathered from the "Street Forum" demonstrated that male clients also need to feel emotional intimacy with other males. The metaphor of hunting can, therefore, be seen to serve as their thread to one another. The male hunters can bond via their camaraderie which, according to Sasson-Levy (2008), is a significant motif in Israel's heroic epics as lifelong relationships that flourish regardless of social or political differences. This is demonstrated in this next post, which was written in response to a complaint that clients on the forum were not contributing enough written reports to the community:

You talk like you went into Lebanon and jumped on a grenade for your friends. Some people can put their hands in their pockets, and some can't. I'm a newly discharged soldier who does not have a lot of money, so I go hunting for about two or three times a month and report it. How will I have more than 100 messages? (January 3, 2013)

The reference to the Lebanon War, ${ }^{4}$ jumping on a grenade, and his own army status is not coincidental. Even though he is trying to oppose the "forced" camaraderie created in the forum, his reaction speaks of the communal ethos of the community in which clients are encouraged to feel affection and camaraderie toward fellow

\footnotetext{
${ }^{4}$ This could be a reference to either the First Lebanon War (1982-2000) or the Second Lebanon War (2006).
} 
hunters. Self-sacrifice is the sign of the hero: "he who dares to rise above his basic instinct for life and fight for the good of his imagined community" (Sasson-Levy 2008 , p. 310). Thus, whether it is an attempt to restore ancient masculinity or an attempt to recreate a masculine military experience, what emerges is the use of the hunting discourse as a way of belonging to the imagined community of men. Hence, for Israeli clients of street-based sex work, the consumption of commercial sex, similar to military service, becomes an arena used for masculine violent 'games' that produce overt signs of masculinity where the object of their power is some form of control over the other while legitimizing this control. At the same time, the fact that they encourage each other to report as much as possible attests to a constant competition over who reports more as a way of validating their masculinity. Competitiveness and camaraderie thus complement each other. Moreover, competitiveness and camaraderie also go hand in hand with a careful and detailed planning of the hunting ritual.

\section{The Importance of Pre-planning}

Unlike previous studies (Bernstein 2001; Monto and McRee 2005) in which streetbased sex consumption was regarded as a casual and opportunistic activity that takes place without prior considerations, data gathered from "Street Forum" reveals that kerb-crawling is a pre-planned and calculated ritual for which the client must prepare. Clients often share various "guides" for novice buyers in order to teach them the main principles of kerb-crawling. This is consistent with findings of how online communities serve as a mechanism for both the legitimization of this activity and the socialization of subcultural conduct norms (Horswill and Weitzer 2018; Janson 2013). As a ritual, kerb-crawling/hunting stresses the importance of the first stage which is pre-planning:

Going hunting is like going out. You need to prep for it. I know that most of the time, it will not be quick but rather a slow and crawling night that will make me work hard to find someone I want. (August 28, 2012 ${ }^{5}$ )

When I go hunting, I take it seriously..., I come clean and perfumed...even my dick gets pre-treatment (and always gets compliments). (July 23, 2012)

Thus, the hunting ritual is also consistent with Zelizer's (2007) claim that the way people use gifts and varied symbols as an economic transaction corresponds to the way they define their relationships with one another. Although cigarettes, alcohol, or drugs may be used as payment on the street, clients often treat them as gifts or small gestures accompanying the payment of money for the sexual act: "I went hunting with a package of wipes, cigarettes, a new CD and three Red Bull cans for the ladies. (July 7, 2012)". Data gathered from "Street Forum" reveals the existence of a distinct ethos between members of the online

\footnotetext{
5 . All the quotes in the paper were originally written in Hebrew and were translated by the author. An effort has been made to remain as faithful as possible to the original meaning of the text.
} 
community which encompasses both the universal repertoire of the hunter as well as the local repertoires of the combat soldier and the Halutz. For example, a member of "Street Forum" wrote the following post as a blessing to other members/hunters in the community before setting off on a "hunt":

Dear friends, I would like to contribute my humble lot in the form of a fire ceremony for the brave hunters who are facing a bold action in foreign lands. May your pledge be faithful, and may you return from your mission in peace. (March 3, 2013)

His "blessing" reflects the meaning of the hunt on the street as a collective masculine ritual involving sacrifice and initiation where the positive qualities of "the brave hunter" are emphasized while there is a scant attention to the fate of that which is killed. The hunting metaphor can thus be seen to play a socialising role. According to Jones (2012), hunting has always been regarded as a masculine activity, in which the character of the heroic hunter is rooted in narratives of taking over and assimilating into land and nature. The heroic archetype possesses the skills of killing and survival and a desire for danger and adventure. Numerous mythologies, therefore, combine national aspirations of pioneering with the development of a hegemonic masculine ideal which allows for interaction with nature, independence, conquest, belonging, and empowerment (Jones 2012). The points of tangency between masculine ceremonies related to hunting and those relating to sex have become a research interest (Anderson and O'Connell Davidson 2003), likewise the connection between hunting, collective masculinity, and sexual courtship (Grazian 2007; Kalof et al. 2004; Luke 1998; Oliver 2013).

However, unlike other societies, Israeli culture lacks any hunting tradition. As mentioned earlier, Israeli society constructs masculinity on the basis of the combat soldier and Halutz repertoires. Both contain similar components to the hunter repertoire including, as mentioned above, courage, endurance, the pursuit of honour, a combative spirit, and physical power. Nevertheless, unlike the universal hunter repertoire, the Israeli masculinity repertoires are bound with racialised social hierarchies. The language chosen by the writer of the "blessing""fire ceremony," "brave hunters," "bold action," and "mission"-reflects the merging of the hunting discourse with a pioneering and a military discourse and establishes the quest for courage, adventure, and heroism as Israeli masculine ideals (Hirsch and Grosswirth Kachtan 2017; Sasson-Levy 2002, 2008). At the same time, under the veil of anonymity, even if the individual does not belong to the "right" ethnic group or has not served as a combat soldier, he can still use the metaphor of hunting as a way to feel part of the local and universal hegemonic masculinity. Thus, as a collective masculine ritual, the consumption of sex on the street and writing about it online has become a classical liminoid ritual (Terner 2008) which creates a temporary sense of commonality between members of the community. It is also present when clients describe the importance of a hunting strategy such as screening. 


\section{Practices of Screening}

Studies on street-based sex workers' strategies (Oselin and Cobbina 2017; Sanders 2005) have highlighted the importance of screening practices before the actual act takes place. According to Armstrong (2014), screening practices operate to assess the dynamics of power and control with potential clients. Screening practices have also become a major issue for street clientele, but for different reasons. While sex workers use screening as an attempt to determine the likelihood that clients will break or keep the agreed terms of the encounter (Sanders 2005), for clients, it is less about gaining trust and more about a celebratory display of power in front of other members of the community.

The waiting might give me a relative advantage.... When the hunter is searching for the girl, the idea is to go at $30-40 \mathrm{~km}$ per hour and to scan all the spots where the girls stand. Sometimes I spent weeks just arriving, driving around, and learning." (March 13, 2013)

These practices are a testimony to the effort the individual is willing to invest in fulfilling his hunting as well as marking himself in front of other members of the community as an experienced and patient veteran hunter. Screening is also part of what clients perceive as a training arena for hunters, teaching them to keep their senses alert to what they define as the inherent dangers of the street:

As a hunter, you should always keep your senses sharpened, be alert and fussy to any scenario. Once you are emotionally involved, you lose a lot of your advantage and are much more exposed to the dangers that lurk in the street. (May 5, 2013)

This quote shows great similarity to the preparation that soldiers undergo before and during their departure for military action. It is well documented how the military has become a dominant platform for the definition and reproduction of hegemonic masculinity (Connell 2005, p. 214). In the Israeli context, SassonLevy (2008) argued that the construction of the Israeli combat soldier involves two seemingly opposing themes: self-control and thrill. While the theme of selfcontrol is characterized by introversion, self-restraint, and self-repression, the theme of thrill accentuates the outward expression of wild, unrestrained feelings, stemming from life-endangering events, adventurous activities, and the unique opportunities that the military offers for intimacy among men.

The previous quote stresses how self-control, combined with other components of hegemonic masculinity such as the need to seek out risk, to be emotionally stoic, and to reject displays of femininity or fear (Connell 2005; Joseph and Black 2012), influence the way Israeli clients perceive street-based sex consumption. Failure for boys and men to live up to these rigid gendered expectations results in shame and humiliation. Thus, learning the hunting practices-with their similarity to militarised practices-is the clients' way of protecting themselves against the danger of failure or humiliation in front of both sex workers and other members of the community. 
The "guides" mentioned above function not only as norms and practices toolkit. They help to establish a client's position in the community as a savvy veteran who can gain an advantage over other clients on the street. For example, one of the veteran clients wrote about what he thinks the hunter needs on the street:

Take it from someone who knows. In the streets, the hunter needs three things: experience, luck, and courage. Experience gives you a lot of confidence, you know the language and the kind of services, you know what to expect, and you can compare. You can "read" the streets, know every hole and alley, can pick up moves ... knowledge is a tremendous force. Luck never hurts. With all the knowledge and experience of where to look, where to wait, and what moves to make, you still need the luck to catch the girl you want....Courage, I have realised, often improves the experience of the street. (August 25, 2012)

Furthermore, for many clients, the practices of screening while cruising the streets are sometimes more fulfilling than the actual sexual act, which becomes almost secondary:

I went home without getting laid...I have noticed that sometimes only the hunting rounds are fun. (October 30, 2012)

In the last two weeks, I have gone out for at least six rounds of hunting. Those who haven't tried these rounds don't know what strength there is in anticipating which girls will be there. In the two weeks that I just visited, I looked around, I learned...Even though I didn't gain sexual release, I gained emotional and mental satisfaction. (October 28, 2012).

These testimonies are similar to what Sanders (2012) found among regular clients of indoor sex work, namely, that sex sometimes became secondary to the emotional intimacy attained in the encounters. This, therefore, challenges the aforementioned claim that street-based sex work serves as only economic transactions. Data shows that sometimes the metaphoric hunt itself is the "drama"; the hunt itself is the objective.

\section{Discussion and Conclusion}

In this article, I have discussed the masculine repertoire of Israeli clients of streetbased sex work. Drawing on the language of the hunter sexual script, we can see how interactions in the sex industry are shaped by the cultural scripts that govern sexual relationships more broadly. The Israeli repertoire, which is based on the sexual script of the hunter, reveals the deep meaning of sex consumption on the street and reflects the way in which universal and local masculine repertoires are negotiated and contested. The consumption of commercial sex has always been seen as a universal cultural practice that signifies a masculine self (Schrock and Schwalbe 2009); I found, however, that it simultaneously reproduces and recaptures the universal patriarchal, heteronormative discourses while also containing local cultural repertoires of masculinity. 
According to Sanders (2008), the sexual script among male clients in commercial sexual relationships does not differ significantly from that of heterosexual men seeking conventional relationships. This is, perhaps, one of the reasons why Israeli male clients use the hunting metaphor since it also serves men during normative courting where they sometimes become the predators and women the hunted prey. Although this explanation challenges the perception of street-based sex work as merely an economic transaction, it does not reveal the deep meaning of the hunting metaphor. Beyond just reproducing the heterosexual script, for Israeli clients, the hunting metaphor has become a channel through which a community of 'warriors' is built.

Under the veil of anonymity, the online community reconstructs traditional men's clubs where men can express their unmet emotional needs such as the need for intimacy among men themselves as well as to experience imposing metaphorical killing, i.e. hunting on the streets, without experiencing themselves as violent in practice. Writing about their sexual encounters on the street enables them to bring up issues which they cannot talk about in daily life. Writing and sharing content in the forums allows clients to get excited once again by the experience and to collectively participate in the private sexual act which, via the written report, becomes a communal sexual act. The communal ethos of hunting, metaphorical killing and being a predator can, therefore, be seen as a reaction to the modern world where online technology enables members to return to their wild inner nature and create male camaraderie while releasing themselves from moral bonds.

The fact that the hunting discourse has become the trademark of the Israeli community teaches us less about the way clients perceive sex workers and more about the clients' needs to create an inner unity and homogeny of hyper-masculinity that covers up any hierarchal boundaries that exist in their daily lives. In Israeli militaristic culture, the (Jewish) combat soldier has achieved the status of hegemonic masculinity and represents good citizenship (Sasson-Levy 2008). However, in the consumption of commercial sex, it doesn't matter whether you belong to a dominant ethnic group, whether you are an Arab or a Jew, or whether you served as a combat or a non-combat soldier; the hunting discourse transcends all of these. For those who served as combat soldiers, it's a way of restoring camaraderie; for those who didn't serve as combat soldiers or didn't serve at all, it's a way of connecting with the hegemonic Israeli masculine repertoires which they may not generally be a part of. Thus, the hunter sexual script, as a flexible repertoire of masculinity, functions as a platform on which power relations between men themselves are publicly displayed and are constantly challenged.

\section{Compliance with Ethical Standards}

Conflict of interest The authors declare that there is no conflict of interest.

Ethical Approval All procedures performed in studies involving human participants were in accordance with the ethical standards of the institutional and/or national research committee and with the 1964 Helsinki declaration and its later amendments or comparable ethical standards.

Informed Consent Informed consent was obtained from all individual participants included in the study. 
Open Access This article is distributed under the terms of the Creative Commons Attribution 4.0 International License (http://creativecommons.org/licenses/by/4.0/), which permits unrestricted use, distribution, and reproduction in any medium, provided you give appropriate credit to the original author(s) and the source, provide a link to the Creative Commons license, and indicate if changes were made.

\section{References}

Agar, M. (1994). Language shock: Understanding the cultures of conversation. York New: William Morrow.

Anderson, B., \& O'Connell Davidson, J. (2003). Is trafficking in human beings demand driven? (A multicountry pilot study no. 15). Geneva: International Organization for Migration.

Armstrong, L. (2014). Screening clients in a decriminalised street-based sex industry: Insights into the experiences of New Zealand sex workers. Australian and New Zealand Journal of Criminology, 47(2), 207-222.

Ben-Ari, E., \& Levy-Schreiber, E. (2000). Body building, character building and nation-building: Gender and military service in Israel. Studies in Contemporary Judaism, 16, 171-190.

Bernstein, E. (2001). The meaning of the purchase: Desire, demand and the commerce of sex. Ethnography, 2(3), 389-420.

Bernstein, E. (2007). Temporarily yours: Intimacy, authenticity, and the commerce of sex. Chicago, IL: University of Chicago Press.

Blevins, K. R., \& Holt, T. J. (2009). Examining the virtual subculture of johns. Journal of Contemporary Ethnography, 38(5), 619-648.

Bourdieu, P. ([1998] 2001). Masculine domination. Stanford, CA: Stanford University Press.

Brents, B. G., \& Sanders, T. (2010). Mainstreaming the sex industry: Economic inclusion and social ambivalence. Journal of Law and Society, 37(1), 40-60.

Brooks-Gordon, B., \& Gelsthorpe, L. (2003). What men say when apprehended for kerb crawling: A model of prostitutes' clients' talk. Psychology, Crime and Law, 9(2), 145-171.

Burghart, K. O. (2018). What's on sale? A discourse analysis of four distinctive online escort advertisement websites. Sexuality and Culture, 22, 316-335.

Busch, N. B., Bell, H., Hotaling, N., \& Monto, M. A. (2002). Male customers of prostituted women: Exploring perceptions of entitlement to power and control and implications for violent behavior toward women. Violence Against Women, 8(9), 1093-1112.

Cabezas, A. (2009). Economies of desire: Sex and tourism in Cuba and the Dominican Republic. Philadelphia, PA: Temple University Press.

Caldas-Coulthard, C. R. (1993). From discourse analysis to critical discourse analysis: The differential representation of women and men speaking in written news. Techniques of Description: Spoken and Written Discourse (pp. 196-208).

Connell, R. W. (2005). Masculinities. Berkeley, CA: University of California Press.

Della Giusta, M., Di Tommaso, M. L., Shima, I., \& Strøm, S. (2009). What money buys: Clients of street sex workers in the US. Applied Economics, 41(18), 2261-2277.

Earle, S., \& Sharp K. (2008a). Sex on the net: Online relations between the men who pay for sex. In S. Holland (Ed.), Remote relationships in a small world. Digital formations (Vol. 41). Oxford: Peter Lang Publishing. https://oro.open.ac.uk/10869/1/EARLE_SHARP_CHAPTER_FOR_DIGITAL_ FORMATIONS.pdf.

Earle, S., \& Sharpe, K. (2008b). Intimacy, pleasure and the men who pay for sex. In G. Letherby (Ed.), Sex as crime (pp. 63-79). New York, NY: Taylor \& Francis.

Ellison, G., \& Weitzer, R. (2017). The dynamics of male and female street prostitution in Manchester, England. Men and Masculinities, 20(2), 181-203.

Gagnon, J. H., \& William, S. (2005). Sexual conduct: The social sources of human sexuality (2nd ed.). New Brunswick, NJ: AldineTransaction.

Gorry, J., Roen, K., \& Reily, J. (2010). Selling yourself? The psychological impact of street sex work and factors affecting support seeking. Health and Social Care in the Community, 18(3), 492-499.

Grazian, D. (2007). The girl hunt: Urban nightlife and the performance of masculinity as collective activity. Symbolic Interaction, 30(2), 221-243. 
Hail-Jares, K., Paquette, C., \& Le Neveu, M. (2017). Meeting the new neighbors: A case study on gentrification and sex work in Washington, DC. In K. Hail-Jares, C. S. Shdaimah, \& C. S. Leon (Eds.), Challenging perspectives on street-based sex work (pp. 51-77). Philadelphia, PA: Temple University Press.

Hirsch, D. (2014). Hygiene, dirt, and the shaping of a new man among early Zionist halutzim. European Journal of Cultural Studies, 18, 300-318.

Hirsch, D., \& Grosswirth Kachtan, D. (2017). Is "hegemonic masculinity" hegemonic as masculinity? Two Israeli case studies. Men and Masculinities, 21(5), 1-22.

Hoang, K. K. (2011). "She's not a low-class dirty girl!" Sex work in Ho Chi Minh City, Vietnam. Journal of Contemporary Ethnography, 40(4), 367-396.

Holt, T. J., \& Blevins, K. R. (2007). Examining sex work from the client's perspective: Assessing johns using online data. Deviant Behavior, 28, 333-354.

Horswill, A., \& Weitzer, R. (2018). Becoming a client: The socialization of novice buyers of sexual services. Deviant Behavior, 39(2), 148-158.

Hubbard, P., \& Sanders, T. (2003). Making space for sex work: Female street prostitution and the production of urban space. International Journal of Urban and Regional Research, 27(1), 75-89.

Huff, A. D. (2011). Buying the girlfriend experience: An exploration of the consumption experiences of male customers of escorts. Research in Consumer Behavior, 13, 111-126.

Huysamen, M. (2018). Queering the "straight" line: Men's talk on paying for sex. Journal of Gender Studies. https://doi.org/10.1080/09589236.2018.1546570.

Huysamen, M., \& Boonzaier, F. (2015). Men's constructions of masculinity and male sexuality through talk of buying sex. Culture, Health and Sexuality, 17(5), 541-554.

Janson, L. (2013). Our great hobby: An analysis of online networks for buyers of sex in Illinois. CAASE: Chicago Alliance Against Sexual Exploitation. Retrieved from https://humantraffickinghotline.org/ resources/our-great-hobby-analysis-online-networks-buyers-sex-illinois.

Jones, K. (2012). Lady wildcats and wild women: Hunting, gender and the politics of show(wo)manship in the nineteenth century American West. Nineteenth-Century Context, 34(1), 37-49.

Jones, Z., \& Hannem, S. (2018). Escort clients' sexual scripts and constructions of intimacy in commodified sexual relationships. Symbolic Interaction, 41(4), 488-512.

Joseph, L. J., \& Black, P. (2012). Who's the man? Fragile masculinities, consumer masculinities, and the profiles of sex work clients. Men and Masculinities, 15(5), 486-506.

Kalof, L., Fitzgerald, A., \& Baralt, L. (2004). Animals, women, and weapons: Blurred sexual boundaries in the discourse of sport hunting. Society and Animals, 12(3), 237-251.

Kaplan, D. (2003). Brothers and others in arms: The making of love and war in Israeli combat units. New York, NY: Haworth Press.

Katsulis, Y. (2010). "Living like a king"': Conspicuous consumption, virtual communities, and the social construction of paid sexual encounters by US sex tourists. Men and Masculinities, 13(2), 210-230.

Kimmel, M. S. (1996). Manhood in America: A cultural history. New York, NY: Free Press.

Kronsell, A. (2015). Sexed bodies and military masculinities: Gender path dependence in EU's common security and defense policy. Men and Masculinities, 19(3), 311-336.

Lahav-Raz, Y. (2016). Behind the discreet curtain: Clients' discourses and the internet as an active actor in the sex industry. Doctoral dissertation. The Ben-Gurion University of the Negev (Hebrew).

Lahav-Raz, Y. (2017). Screen carnival: The development of a unique jargon among clients of the Israeli sex industry. Israel Studies in Language and Society, 10(2), 36-52. (Hebrew).

Lahav-Raz, Y. (2019a). The prosumer economy and the sex industry: The creation of an online community of sex prosumers. Journal of Cultural Economy. https://doi.org/10.1080/17530350.2019.16461 59.

Lahav-Raz, Y. (2019b). Narrative struggles in online public arenas: The Facebook feminist sex wars on the Israeli sex industry. Feminist Media Studies. https://doi.org/10.1080/14680777.2019.1642227.

Lomsky-Feder, E., \& Rapoport, T. (2003). Juggling models of masculinity: Russian-Jewish immigrants in the Israeli army. Sociological Inquiry, 73, 114-137.

Luke, B. (1998). Violent love: Hunting, heterosexuality, and the erotics of men's predation. Feminist Studies, 24(3), 627-655.

Mazali, R. (1993). Military service as initiation rite. Challenge, IV(4), 36-37.

Milrod, C., \& Weitzer, R. (2012). The intimacy prism: Emotion management among the clients of escorts. Men and Masculinities, 15(5), 447-467. 
Monto, M. A., \& McRee, N. (2005). A comparison of the male customers of female street prostitutes with national samples of men. International Journal of Offender Therapy and Comparative Criminology, 49(5), 505-529.

Oliver, K. (2013). Hunting girls: Patriarchal fantasy or feminist progress? Americana: The Journal of American Popular Culture (1900-Present), 12(1), 1-15.

Oselin, S. A., \& Cobbina, J. E. (2017). Holding their own: Female sex workers' perceptions of safety strategies. In K. Hail-Jares, C. S. Shdaimah, \& C. S. Leon (Eds.), Challenging perspectives on street-based sex work (pp. 78-99). Philadelphia, PA: Temple University Press.

Ostriker, A. (1986). Stealing the language: The emergence of women's poetry in America. Boston: Beacon Press.

Sagar, T. (2009). Anti-social powers and the regulation of street sex work. Social Policy and Society, 9(1), 101-109.

Sagar, T., \& Croxall, J. (2012). New localism: Implications for the governance of street sex work in England and Wales. Social Policy and Society, 11, 483-494.

Sagar, T., \& Jones, D. (2013). The local governance of street sex work in the United Kingdom: Views from the shop floor. International Criminal Justice Review, 23(2), 132-148.

Sanders, T. (2001). Female street sex workers, sexual violence, and protection strategies. Journal of Sexual Aggression, 7(1), 5-18.

Sanders, T. (2004). The risks of street prostitution: Punters, police and protesters. Urban Studies, 41(9), 1703-1717.

Sanders, T. (2005). Sex work: A risky business. Cullompton: Willan.

Sanders, T. (2008). Male sexual scripts: Intimacy, sexuality and pleasure in the purchase of commercial sex. Sociology, 42(3), 400-417.

Sanders, T. (2012). Paying for pleasure: Men who buy sex. Abingdon: Routledge.

Sanders, T., O’Neill, M., \& Pitcher, J. (2009). Prostitution-sex work, policy and politics. London: Sage.

Santo, Y., Carmeli, A., \& Rahav, G. (2016). The national survey on the phenomenon of prostitution in Israel. The Ministry of Social Affairs and Social Services and the Ministry of Public Security, Israel (Hebrew).

Sasson-Levy, O. (2002). Constructing identities at the margins: Masculinities and citizenship in the Israeli army. The Sociological Quarterly, 43(3), 357-383.

Sasson-Levy, O. (2003). Military, masculinity, and citizenship: Tensions and contradictions in the experience of blue-collar soldiers. Identities: Global Studies in Culture and Power, 10, 319-345.

Sasson-Levy, O. (2008). Individual bodies, collective state interests: The case of Israeli combat soldiers. Men and Masculinities, 10(3), 296-321.

Schrock, D., \& Schwalbe, M. (2009). Men, masculinity, and manhood acts. The Annual Review of Sociology, 35, 277-295.

Shumka, L., Strega, S., \& Hallgrimsdottir, H. K. (2017). “I wanted to feel like a man again”: Hegemonic masculinity in relation to the purchase of street-level sex. Frontiers in Sociology, 2(15), 1-15.

Simon, W., \& Gagnon, J. H. (1986). Sexual scripts: Performance and change. Archives of Sexual Behavior, 15(2), 97-120.

Spender, D. (1980). Man made language. London: Routledge \& Paul Kegan.

Suler, J. (2004). The online disinhibition effect. CyberPsychology and Behavior, 7(3), 321-326.

Swidler, A. (1986). Culture in action: Symbols and strategies. American Sociological Review, 51, 273-286.

Terner, V. ([1969] 2008). The ritual process: Structure and anti-structure. Newark: Rutgers University.

Tyler, M., \& Jovanovski, N. (2018). The limits of ethical consumption in the sex industry: An analysis of online brothel reviews. Women's Studies International Forum, 66, 9-16.

Vaughn, M. P. (2019). Client power and the sex work transaction: The influence of race, class, and sex work role in the post-apartheid sex work industry. Sexuality and Culture. https://doi.org/10.1007/ s12119-019-09594-7.

Weitzer, R. (2012). Legalizing prostitution: From illicit vice to lawful business. New York, NY: New York University Press.

Wiederman, M. W. (2015). Sexual script theory: Past, present, and future. In J. DeLamater \& R. F. Plante (Eds.), Handbook of the sociology of sexualities (pp. 7-22). Switzerland: Springer.

Zelizer, V. A. (2007). The purchase of intimacy. Princeton, NJ: Princeton University Press.

Zheng, T. (2009). Red lights: The lives of sex workers in post socialist China. Minneapolis, MN: University of Minnesota Press. 
Publisher's Note Springer Nature remains neutral with regard to jurisdictional claims in published maps and institutional affiliations. 